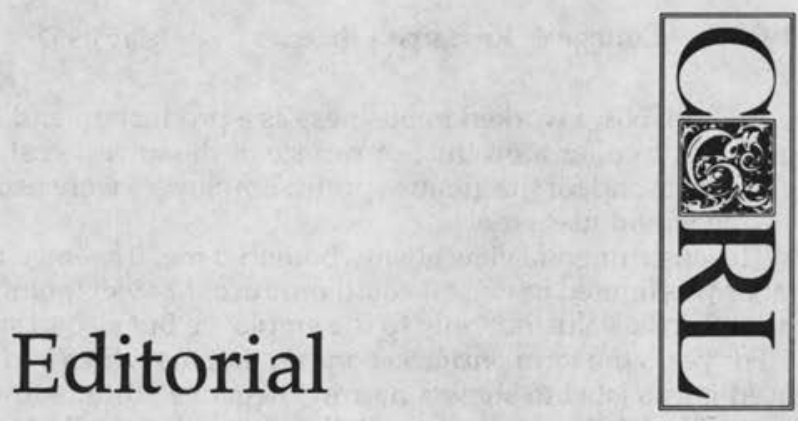

\title{
Reconciling Viewpoints: Proudfoot versus Churchwell
}

Abram Collier's "Debate at Wickersham Mills" won the prestigious McKinsey Award as the best Harvard Business Review article for 1959. The circumstances of the hypothetical debate and a related mock election are as follows:

A family-owned textile company in precarious condition, Wickersham had just lost its president and CEO [chief executive officer] by death. At the following meeting of stockholders, four members of the family offered themselves as possible successors, outlining the strategies and philosophies they would adopt if elected. . . . Jennifer's views were oriented to production, Charles's to organization, Ryan's to the investor, and Pamela's to the consumer.*

Jennifer received 20 percent of the vote, Charles 22 percent, Ryan 10 percent, and Pamela 48 percent.

A second election was held just last year. The results are reported in the January 1987 issue of $H B R$. Did opinions change significantly over the past twenty-six years? They certainly did! More than 2,500 HBR readers chose Pamela again, but this time her margin had increased from 48 to 57 percent of the vote. The major loser was Jennifer, the productionoriented candidate, who lost nine percentage points. Charles lost a point and Ryan gained a point.

Collier concludes that Pamela's philosophy of service to the consumer led her to win by an overwhelming majority. Determining what the consumer needs and wants seems like an obvious priority, but as the author notes, "In the early decades of this century, surely, the Wickersham vote would have produced quite different results. . . . The prevailing goal of a business then was to make something good, to produce it cheaply, and to sell it to as many customers as possible." A production orientation ruled with a tight fist.

My vote would have gone to the consumer candidate. Go out and find what the consumer wants or needs-actual and latent, and then design, produce, and market the product or service that meets the want. This type of consumer-oriented behavior is extraordinarily different from how we as librarians behave. Nevertheless, my guess is that 95 percent of us would choose the consumer candidate.

Collier does not believe, however, that any manager can rely exclusively on one point of view. "Unquestionably [each viewpoint] can be appropriate and necessary for certain circumstances and no one viewpoint is adequate for all."

As the retired CEO of New England Mutual Life Insurance Company, Collier believes "an executive's life consists of reconciling points of view that often seem, and sometimes are irreconcilable. . . . What is truly evil," he says, "is for a person in any position of leadership to have an unshakable conviction that he or she knows beyond any doubt what is right and wrong, what is good and bad."

*The original all-male list of names was changed for editorial purposes. 
In the 1960s, I worked in business as a production and inventory control specialist. The goal was to offer a product or service at the lowest cost, with the maximum output per employee, and for the greatest profit. Employees were usually viewed instrumentally, i.e., as one would use a tool.

This instrumental view always bothered me. It seemed to imply that the value of human labor was limited to what it could produce. My viewpoint, on the other hand, is that work has intrinsic value not only to the employee but also to society.

For years the term production-oriented left me with a bad taste. I avoided using it or else I used it as a label to show a narrow, negative attitude toward others. At the same time, I recognized the need to approach the physical or intellectual activity of labor and the output of labor from a new perspective. Here is where I found a unity in the techniques and concepts related to the design of work and the quality of work life.

As America's competitive advantage eroded, I began to ask myself more searching questions about the social value and costs related to what libraries produce. I had listened to stories about catalogers who cataloged an average of three books a day. I read reports about collections with a no-use rate as high as 40 percent of total holdings. I saw librarians at the reference desk average two or three questions per hour.

At this point, the term production began to have a new meaning for me. I could no longer set it aside so conveniently. I became willing to ask the awkward questions that relate to what, how much, and at what cost do we produce library products and services. In fact, throughout the United States there seems to be a greater willingness by more people to ask such questions.

How we answer the questions is far more complicated. A return to an industrial sweatshop mentality is unacceptable. Values need to be reconciled. Within this context progress is possible.

Because we have made notable progress in our positive orientation toward consumers, because we have become more enlightened in our attitudes toward the value and potential of our employees, and because we have been troubled by the United States' productive capacity, it is unfortunate that we have to witness the sad episode at Washington University.

A business consultant firm, Proudfoot Associates, is called in by the vice president to whom the dean of library services, Charles Churchwell, reports. The firm is asked to study the library.

The consultants enter. Gather time and motion data. Exit. Report.

Proudfoot makes a series of recommendations. Cut staff and add books. Apparently, all library personnel are excluded from the study and the entire decision-making process. I called and asked for a copy of the Proudfoot report. "There is none," said the respondent. "What do you mean?" I asked. "Can't you get me a copy?" "There is no written report that I know of," was the response. Franz Kafka would have been proud of the plot.

It appears that the library staff have been used just as instrumentally as if they had been drones bound to a production line. Proudfoot, allowed by the vice president to impose its values over the assumed protests of Churchwell, does so. The cultural, societal, and organizational values of libraries, as well as those of higher education, play no observable role in the consultant's deliberations. Rather, they are violated.

Dean Charles Churchwell resigned in the face of these recommendations. In Library Journal (March 15, 1987) we learn

According to Churchwell, business consultants have no place telling library managers how to operate. He welcomes peer group evaluation of the library, but the Proudfoot system "goes against everything I stand for as a professional librarian." The system, he says, is "demeaning to librarians . . . shows callous disregard of professionalism." Proudfoot's system treats people as factory workers, Churchwell remarked: "I'm not a floor manager."

In the March 23, 1987, LJ Hotline it is noted:

- Staff members, as of the past week, are no longer required to fill out the Proudfoot forms that detail and time every action. 
- The requirement that no books be bought unless they have the specific approval of a faculty member is also off.

- The staff assigned to a retrospective conversion project have been taken off it. . . . The recon project was apparently launched by Proudfoot in the mistaken notion that it was indeed the same as a cataloging backlog project.

This is a sorry, but classic, case study of what can go wrong when the opinions of experts, i.e., the library staff, are rejected, when the values of others are deemed unimportant, and when the viewpoints of one group are imposed on a different culture, a culture in which service to the consumer is neither profit nor production oriented.

Now it is time to gather the pieces together. Unfortunately, the fabric of trust may have been so tattered that the miscalculations of a few minutes may take years to rebuild.

There is a lesson to be learned from recent events at Washington University. The production-oriented recommendations of Proudfoot found even less support than the production-oriented candidate at Wickersham Mills.

Production does not have to be a dirty word. It must, however, be guided so that equitable, rationale, and clear-sighted service alternatives are implemented. They should help the consumer and should demonstrate sensitivity and regard for the expert knowledge that professionals can contribute toward the search for improved products and services.

CHARLES MARTELL

\section{In Forthcoming Issues Of College \& Research Libraries}

Libraries and Computing Centers: A Blueprint for Collaboration by Richard M. Dougherty Bibliographic Instruction: Planning for the Electronic Information Environment by Harold B. Shill

The Configuration of Reference in an Electronic Environment by Jane P. Kleiner

Murfin's Reference Assessment Instrument by Marjorie E. Murfin and Gary M. Gugelchuk

Creative Thinking in Decision Making: A Bibliography by Carl H. Losse and Arlyle Mansfield Losse

Survey of Online Systems by John A. Camp, Grace Agnew, Christina Landram, Jane Richards, and Judith Shelton

Selected Reference Books of $1986-87$ by Eileen Mcllvaine 